\title{
USING GROUP TECHNOLOGY, SIMULATION AND ANACYTIC MODELING IN THE DESIGN OF A CELLULAR MANUFACTURITG FACILITY
}

\author{
Michael C. Mills \\ McDonnell Douglas Aerospace Information Systems \\ McDonnell Douglas Helicopter Company \\ Centinela Avenue and Teale Street \\ Culver City, California 90230
}

\begin{abstract}
1. Cell definition.

2. Cell plamning.

3. Cell configuration.

4. Cell management.
\end{abstract}

McDonnell Douglas Helicopter Company (MDHC), designer and manufacturer of military and commercial helicopters, is currently instituting a major modernization program. A resource consolidation project has been initiated as part of this modernization program. One of the primary goals of this project is to consolidate the production resources into a cellular manufacturing environment resulting in a projected reduction in the current manufacturing space requirements by up to $50 \%$. Other goals of the consolidation project include:

1. Reduction in part/lot throughput time.

2. Reduction in work-in-process inventory levels.

3. Reduction in wait-move-queue times.

4. Increase in machine tool utilization.

Four key areas are basic to the successful design and implementation of a cellular manufacturing environment:

An approach to this project has been formulated that will result in the initial implementation of one prototype manufacturing cell supported by a shared manufacturing resource zone. The following manufacturing technologies have been used to address the above noted areas:

1. Group technology analysis.

2. Simulation modeling.

3. Process flow analysis.

4. Artificial Intelligence.

The performance of this cellular manufacturing configuration will be monitored through a data collection system and the results used as the basis for the design and implementation of the remaining manufacturing cells.

\section{INTRODUCTION}

The current consolidation project is being carried out at the fabrication facility located in Culver City, California. The fabrication processes supported at this facility include machining, turning, sheet metal forming, composites and composite assembly. The initial cellular design efforts are being focused towards the machining and turning areas. The near term objective of the consolidation project is to implement the first prototype manufacturing cell during the first quarter of 1987 .

The approach developed to facilitate the design and implementation of manufacturing cells was structured around a set of working rules. The primary rule being cell definition will be determined by the manufacturing requirements of the various part families. Other working rules include the following:

1. Fabricated parts do not have to originate or complete the manufacturing process from within the cell.

2. Parts may leave and reenter a manufacturing cell.

3. No major machine tools will be purchased.

4. Current process planning will be modified as required.

5. A shared resource zone concept will be utilized during the cell design process. In order to maximize the utilization of the current manufacturing resources, multicells will be supported by a shared resource zone.

6. Lot integrity will be maintained within the cell.

7. A hierarchical priority scheme will be used in the simulation modeling and cell management rules. Priority levels will be set on parts, lots and machine tools.

8. Permanent machine tool setups will be maintained wherever possible.

The traditional approach Manufacturing Resource Planning (MRP) takes in evaluating manufacturing capabilities is not resource sensitive nor cognizant of the real time dynamics involved in a manufacturing environment. It views this environment as having infinite capacity and schedules it accordingly. It is the intent of this project to define the interrelationships between the various manufacturing cells and control the intercellular and intracellular dynamics through an Artificial Intelligence (AI) based Cell Management System (CMS). The Cell Management System is intended to manage the resources within a cell or between cells in accordance with a specific production strategy. Two strategies will be modeled for the prototype manufacturing cell:

1. Minimize part throughput time.

2. Minimize work-in-process inventory levels.

It is anticipated that the manufacturing cell will be managed differently depending on the production strategy employed. The CMS is intended to augment the current production systems including MRP, Master Scheduling, Shop Floor Control and so on. Alternate routings including Numerical Control (NC) part programs will be used in the development of the CMS knowledge base.

A manufacturing cell data collection system based on bar codes will be developed and implemented in the prototype manufacturing cell. The real time data collected through this system will be used to drive the simulation models and develop the various production scenarios required to augment the manufacturing strategies. 
M. C. Mills

\section{CLASSIFICATION AND CODING}

A manufacturing relational database was developed and the process planning datasets were downloaded from the MDHC data center. We coded 2143 in-house machined and sheet metal parts using the MDC corporate classification and coding system. This code structure allows 32 part, material and manufacturing attributes to be described. A relational model was developed which allows potential cells to be analyzed and reports generated.

\section{GROUP TECHNOLOGY ANALYSIS}

Traditional approaches to group technology have centered around grouping parts by the similarities between their physical characteristics. These characteristics are generally engineering oriented. Most popular class code systems are structured to satisfy engineering requirements for design retrieval and design standardization.

The group technology approach used in this project defines part families according to the dominant relationships existing between their characteristics. This satisfies the initial project requirement that cell definitions be driven by the manufacturing requirements of the appropiate families. In order to utilize this approach, it was necessary to revise the classification code structure and increase the number and types of manufacturing attributes.

A group technology analysis system was developed incorporating the use of advanced statistics. The primary analysis is handled by factor analysis and varimax rotation routines. The group technology analysis system determines the significant, dominant relationships existing between the attribute sub-values and determines the range of these values required to define a part family. This system allows any number of engineering, material and manufacturing attributes representing a group of parts to be analyzed and their dominant relationships ascertained.

Group technology analysis was conducted on the following classes of parts:

\begin{tabular}{lc} 
PART CLASS & SAMPLE SIZE \\
\hline Milled Parts & 314 \\
Turned Parts & 246 \\
Sheet Metal Parts & 357 \\
\hline Total & 917
\end{tabular}

The following attributes were selected for the initial group technology analysis:
1. Part Shape.
8. Quantity.
2. Material.
9. Lot Size.
3. Material Condition.
10. No. of Operations.
4. Part Thickness.
5. Part width.
11. Setup time.
12. Run Time.
6. Part Length.
7. Part Tolerance.
13. Complexity.
14. Total Time.

The following attributes are in the process of being collected or synthesized as they are considered important for future analysis:

1. Manufacturing costs at the process level.

2. Work-in-process inventory levels.

3. Wait-move-queue times.

4. Machine tool characteristics.
The following potential manufacturing cells have been identified through group technology analysis. These cells include:

\begin{tabular}{clcc} 
NO. & CELL TYPE & \%PARTS & \%HOURS \\
\hline 5 & Milled & $16 \%$ & $48 \%$ \\
4 & Turned & $13 \%$ & $29 \%$ \\
8 & Sheet metal & $45 \%$ & $8 \%$ \\
& Misc. & $26 \%$ & $15 \%$ \\
\hline 17 & & $100 \%$ & $100 \%$
\end{tabular}

Group technology analysis of the milled parts datasets has resulted in the identification of the following five potential manufacturing cells:

\begin{tabular}{lcccc} 
CELL & \# PARTS & \% PARTS & \# HOURS & \% HOURS \\
\hline M1 & 6 & $1.70 \%$ & 48729.93 & $25.23 \%$ \\
M2 & 34 & $9.66 \%$ & 32292.00 & $16.72 \%$ \\
M3 & 217 & $61.65 \%$ & 50390.47 & $26.10 \%$ \\
M4 & 37 & $10.51 \%$ & 33090.11 & $17.13 \%$ \\
M5 & 58 & $16.48 \%$ & 28603.72 & $14.82 \%$ \\
\hline & 352 & $100.00 \%$ & 103115.23 & $100.00 \%$
\end{tabular}

Cell M2 was selected as the first prototype cell to be placed into production. It will fabricate Electro-SlagRemelt (ESR) ordinance and Apache helicopter parts. The 34 milled parts selected through group technology analysis to run in Cell M2 can be described as follows:

1. Large steel.

2. Tight tolerance.

3. High complexity.

4. High labor hours.

The following primary, dominant attribute sub-values were selected through group technology analysis to form the criterion by which parts were selected to be fabricated by Cell M2:

1. Material $=$ Stainless steel or steel alloy.

2. Width $>7.00$ inches.

3. Length $>8.75$ inches.

4. Tolerance $< \pm 0.015$.

5. No. of major operations $>5$.

6. Major Run Time $>5$ hrs.

\section{SIMULATION MODELING}

The preliminary output requirements for the high level and detailed level designs of Cell M2 through simulation modeling include:

1. Reduced throughput time for critical parts.

2. Improved process utilization.

3. Reduced work-in-process inventory levels.

4. The production scenarios required to drive the CMS. Two approaches have been taken in developing simulation models of potential manufacturing cells. High level simulation models are used to validate the cells as defined through group technology analysis. Detailed level simulation models are used to design the cells and develop the various cell management scenarios.

High level simulation models were developed using a commercially available simulation product. The following datasets used to drive this model include: 
1. No. of hours worked per day.

2. No. of days worked per year.

3. A list of all the manufacturing resources required by the appropriate family of parts from the time the part first enters the cell until the part finally leaves the cell. These resources include:

1. In cell.

2. In the shared resource zone.

3. Out of cell.

4. Out of plant.

4. The annual production requirements of each part including spares.

5. The lot size of each part.

6. The routing of each part.

7. Tool maintenance and down time records.

8. Production rework and scrap rates.

Results from the analysis of the high level simulation model validate the initial cell configuration through measuring the following parameters:

1. Part/lot throughput time.

2. Machine tool utilization.

3. Work-in-process inventory at the part, machine tool and operation levels.

Detailed level simulation models incorporate the same datasets as the high level models. They also include the ability to set priority levels and to trap data at all critical points within the model. These models are used for the actual design of the cells. Through the use of priority flags, optimized part routings are developed to achieve different production strategies. Lot sizes are varied to satisfy the individual requirements of each cell.

Manuplan was used for all high level simulation modeling. Manuplan is a generic, discrete event simulation model obtained from Network Dynamics, Inc. located in Boston, Mass. Detailed level simulation modeling was accomplished with an internal model developed from SLAM II, a simulation language obtained from Pritsker and Associates located in West Lafayette, Indiana.

High level Manuplan simulation models were developed for manufacturing Cell M2. Production availability was based on a 3 shift, 22.5 hour day and 240 manufacturing days per year. A high level simulation model for Cell M2 was run with a $50 \%$ increase in annual production requirements to test the cell's reaction to a production overload condition. High level simulation analysis of the current planning for the parts scheduled to run in Cell M2 has highlighted the following conditions:

1. Lot sizes were too large resulting in higher throughput times and excessive work-in-process inventory levels.

2. Low machine tool utilization.

3. Bottlenecks are created at the out of cell and out of plant operations. These operations will have to be monitored and reviewed after the implementation of Cell M2.

4. In cell quality inspection will reduce throughput times.

Process flow models were developed and the physical layout of Cell M2 was developed from the analysis of these models. Machine tool loading, part moves, input and output queue requirements and major traffic patterns were analyzed in the process flow model. A simulation model of Cell M2 was run over a 27 -month period using the MDHC generic model. A three month time span was used to stabilize the system and the subsequent two year continuation run was used to analyze the performance of the cell model. The results indicated current production requirements can be achieved with a reduced overall throughput time. Preliminary analysis of comparable models of Cell M2 developed both in Manuplan and SLAM II show the Manuplan results to be up to $5 \%$ on the high side.

\section{FUTURE PLANNED PROJECT ACTIVITIES}

The initial shared manufacturing resource zone is planned to service both Cell M1 and Cell M2. These two cells fabricate very similar parts and use basically the same types of manufacturing resources. The major difference between the two types of parts is material specification. Group technology analysis has defined Cell M1 to process parts that exhibit the following characteristics:

1. Large aluminum.

2. Tight tolerance.

3. High complexity.

4. High labor hours.

The following primary, dominant attribute sub-values were selected through group technology analysis to form the criterion by which parts were selected to be fabricated by Cell M1:

1. Material $=$ Aluminum.

2. Width $>7.00$ inches.

3. Length $>8.75$ inches.

4. Tolerance $< \pm 0.015$.

5. No. of major operations $>5$.

6. Major run time $>5$ hrs.

It is planned to bring Cell M1 and the shared resource zone on line during the third quarter of 1987. The high level and detailed level design efforts on Cell $\mathrm{Mr}$ and the shared resource zone will parallel the detailed design efforts currently under way on Cell M2. Detailed design and analysis of manufacturing Cell M2 includes variations of the following attributes:

1. Lot sizing.

2. Priority ranking:

1. Parts.

2. Lot sizes.

3. Process queues.

3. Shared resource zones requirements.

4. Dedicated machine tool setups.

Cell M2 will be debugged and fine tuned using actual cell performance data. Cell management strategies will be developed for utilizing the cell under various situations and benchmarked in Cell M2 under production conditions. A prototype cell management system is in the process of being developed and will be implemented in Cell M2 during the second quarter of 1987. The Cell Management Sys- 
M. C. Mills

tem will contain prototype simulation, planning and routing modules. 